\title{
Employement of the First Graduates of the Department of Exercise and Sport Education in the Disabilities: A Qualitiative Research
}

\author{
Melike Esentas ${ }^{1}$, Pınar Guzel ${ }^{1}$, Mehmet Vural ${ }^{2}$ \\ ${ }^{1}$ Manisa Celal Bayar University, Sport Sciences Faculty, Manisa- Turkey \\ ${ }^{2}$ Gaziantep University, Physical Education and Sport Department, Gaziantep- Turkey \\ Correspondence: Melike Esentas, Manisa Celal Bayar University, Sport Sciences Faculty, Manisa-Turkey.
}

Received: January 7, 2019

doi:10.11114/jets.v7i3.3954
Online Published: February 22, 2019

URL: https://doi.org/10.11114/jets.v7i3.3954

\begin{abstract}
The aim of this study was to examine the views of the first graduates of the Exercise and Sports Department for Disabled on the employment situation and their attitudes towards disability. In the research we tried to determine the opinions of the first graduates of the Exercise and Sports Education Department for Disabled about the employment issues using the case study method among the qualitative research techniques. The study group of the research was constituted 11 participants who are the first graduates of the Exercise and Sports Department for Disabled. Semi-structured interview technique was used as data collection method in the study. The two stage interview form was consisted of the participants' personal information and the questions prepared about the research topic. Content analysis was used to analyze the data obtained from participants' views. Within the scope of this analysis technique the data coded via NVIVO software program. According to the results, the following four themes came up regarding the opinions of the first graduates of the Exercise and Sports Department for Disabled: "Future of the exercise and sport department for disabled", "Employment", "Gains in employment field" and "Attitudes towards the disabled".In our country, it is necessary to meet the employment expectations of the graduates of this department, opportunities for socialization of the disabled individuals, mostly concentrated in the field of sports and thus ensuring the social integration of these individuals. It has been concluded that these people will contribute to the development of this field by developing important projects and job opportunities for national and international development on behalf of the country.
\end{abstract}

Keywords: department of exercise and sport education in the disabilities, employement, qualitiative research

\section{Introduction}

Education activities which are effective in learning the society they live for people and in learning and gaining the culture, lifestyle and rules of the society, an important social process with this purpose, professional trainers have an important role in the process of developing all skills and behaviors of the disabled people.

The most effective methods that are used for sportive activities in the education for disabled people are the techniques which include most of action. People with disabilities can learn more quickly and simply in sportive activities. During the trainings, both drama and group games and sportive exercises may vary depending on the disability. Many methods in education of disabled persons are used as teaching methods. But, while choosing appropriate methods in teaching of sportive skills, the disability situation of the person should be taken into consideration. For example, it is important to remember that people with intellectual disabilities learn the information in step by step and with clear forms (Arslan, 2014). The sportive activities increase the quality of life of disabled people and also create a social environment for them to realize themselves (Girgin, 2003).

The requirement to act is very important for the disabled as well as everyone. People with disabilities, regardless of disability, should gain life motivation and social adherence by participating in exercise and sporting activities. Sport and physical activity offer a chance for social integration for the disabled. In many studies, it is accepted that as a result of the interaction between skill and success during physical activities, it contributes to the development of positive self in the individual (Gallahue and Omzun 1995; Payne and Isaacs, 2005) and it is said that the integration of disabled people 
to the society through sports, contributes to the level of self-confidence, biological and psychological well-being (Hannon,2005; Sherrill,2010). Disabled people who participating in sportive competition processes, develop their competitiveness by experiencing winning and losing. The disabled people learn to deal with the disability in his life as an athlete in the competition environment and learn to overcome all negative process in the life. This positive effect emerged a social integration.

Sport is not only used in physical and psychological education of the individual, but also helps individuals to be aware of their responsibilities (Alpman, 2001). Sports is an important activity that accelerates the socialization process, develops cooperation, personal discipline, and provides social benefits. While people with disabilities face major problems in city life and transportation, it is obvious that there is an urgent need for professional trainers who are specially trained in this area. These trainers contribute to the life quality of the disabled people by sportive activities, strengthen body muscle and assistive exercise for their rehabilitation (Arslan, 2010).

While physical education and sport department for disabled people, in which disabled people are trained in terms of sportive skills, have not yet opened in Turkey, European countries have opened enough educational institution. For example; German Koln Sport Academy (Sporthochschule), Sport and Rehabilitation Department for Disabled (Institut für Rehabilitation und Behinderungsport) has educated special sport teacher for disabled people. In the United States, many universities are trained teacher for disabled people with teacher training program. In developed countries, they have already implemented educational programs of sport for disabled people (Arslan, 2010). Department of Exercise and Sports Education for the Disabled that will contribute to the socialized especially in terms of sport of the people with disabilities, was opened in Turkey. Those who graduated from this department should be given satisfactory opportunities. Thus, country may be developed and may have an important position in international status.

In this way, it should be ensured that disabled people are in sporting activities without being away from social life. Various competitions and sportive organizations must be organize and the country, institution, federations and regional management services disabled people within the state, institutions, organizations, federations and regional management services that will enable disabled individuals to live in full motivation.

The purpose of this study was to examine of employment situation of first graduates of the Department of Exercise and Sports Education for the Disabled and opinions on their attitudes towards the disabled people.

\section{Method}

\subsection{Research Design}

In the study, the opinions of the graduates of the Department of Exercise and Sports Education for the Disabled were tried to be determined from the qualitative research techniques by using the case study method. Qualitative research can be defined as a research which is used qualitative data collection methods such as observation, interview and document analysis, and a qualitative process for realization of perceptions and events in a realistic and holistic manner in a natural environment (Cohen et all., 2010; Ritchie and Lewis,2003;Yıldırım and Şimşek, 2003). According to Merriam (2013), qualitative research does not include generalizations about what will happen in the future but tries to understand the nature of the place where the event came out. The aim of the qualitative research method is to provide a detailed description of people and cultures.

\subsection{Study Group}

The study group is composed of 11 participants being the first graduates of 2016-2017 academic year in Inonu University Department of Exercise and Sports Education for the Disabled which is the first department accepting students in this field in Turkey (Table 1). "Convenience sampling" method among the "purposeful sampling" methods were used in this research. The personal information 11 participants constituting the study group is given in Table 1.

Table 1. Personal information of the participants

\begin{tabular}{lllll}
\hline Participants & Gender & Age & Job & Marital Status \\
\hline P1 & Female & 25 & Not Working & Single \\
P2 & Female & 26 & Housewife & Married \\
P3 & Male & 26 & Graduate Student & Single \\
P4 & Female & 24 & Not Working & Single \\
P5 & Male & 24 & Military Personal & Single \\
P6 & Female & 25 & Graduate Student & Single \\
P7 & Male & 25 & Graduate Student & Single \\
P8 & Male & 25 & Not Working & Single \\
P9 & Male & 25 & Not Working & Single \\
P10 & Male & 24 & Not Working & Single \\
P11 & Female & 25 & Not Working & Single \\
\hline
\end{tabular}




\subsection{Data Collection}

Semi-structured interview technique was used as the data collection tool in the study. The interview form used in the research is composed of two parts as personal information form of the participants and the questions prepared related to the research topic. The relevant literature review was performed during the preparation of questions and a draft form was prepared with the questions thought to ensure answering the research questions. Open-ended questions were included in the interview form to enable participants in the research group to explain their views without limitation. After taking expert opinions on the interview form prepared, interview questions were finalized.

Before the interviews, each participant was informed about why and for what purpose the interview was made with the interview form prepared and the participants were asked for their voluntary participation for the interviews. It was paid attention to hold the interviews in a quiet place.

\subsection{Data Analysis}

Content analysis was used to analyze the data obtained from the views of the participants. The fundamental process in content analysis is to bring together similar data in the context of specific concepts and themes and to interpret them by organizing in a way that the reader can understand (Yıldırım and Şimşek, 2008). Within the scope of this analysis technique, the data obtained from the study were handled separately by 3 (three) people and coded using the NVIVO software program and these codes were thematized.

\section{Findings}

The participants expressed their opinions about the future of the Department of Exercise and Sports Education for the Disabled that there wouldn't be any problem of employment (Private and Public sector) and appointments would be made immediately (Public). Some of the opinions of participants are as follows;

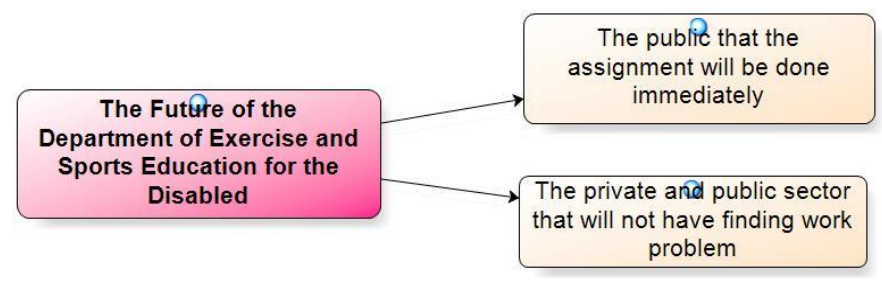

Model 1. The Future of the Department of Exercise and Sports Education for the Disabled

P1: After a 5-year Equipped Training and 50\% of us studying abroad, we were told that we could provide training with very good salaries without any problem of appointments in state and private schools and rehabilitation centers as the owner of good careers.

P3: On the first days we started to study this department, they told that we were very lucky to be in this department due to being a first in Turkey, we would start working right after graduation without the problems of KPSS, the successful students would be sent to Germany to study few semesters there, the graduates of this department would never suffer from the problems of employment, appointment etc. and we could even work in physical therapy centers easily as we took health classes.

P10: It was told that the department was unique in Turkey and the need for employment in this field was high and we could easily find jobs in public and private sector.

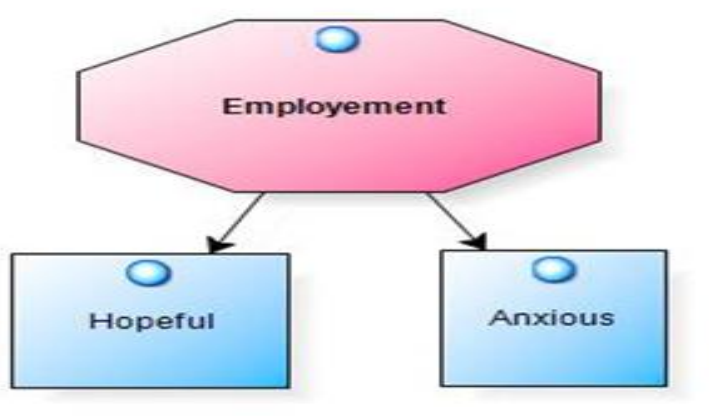

Model 2. Employment of the Department of Exercise and Sports Education for the Disabled 
The participants told that they were hopeful and anxious about the employment before graduating from the Department of Exercise and Sports Education for the Disabled. Some of the opinions of participants are as follows;

P2: What was said about the future of the department was always positive, but nothing was formal and I was constantly worried about whether I could have a job when I graduated in my name.

P8: Before graduating, I thought that public and private sector needed so many people to employ in this area since I was aware of the importance given to the disabled field in Turkey.

P11: I thought that if I really improved myself in this area, I could easily find a job and work in any way. Because it was a really unfinished field.

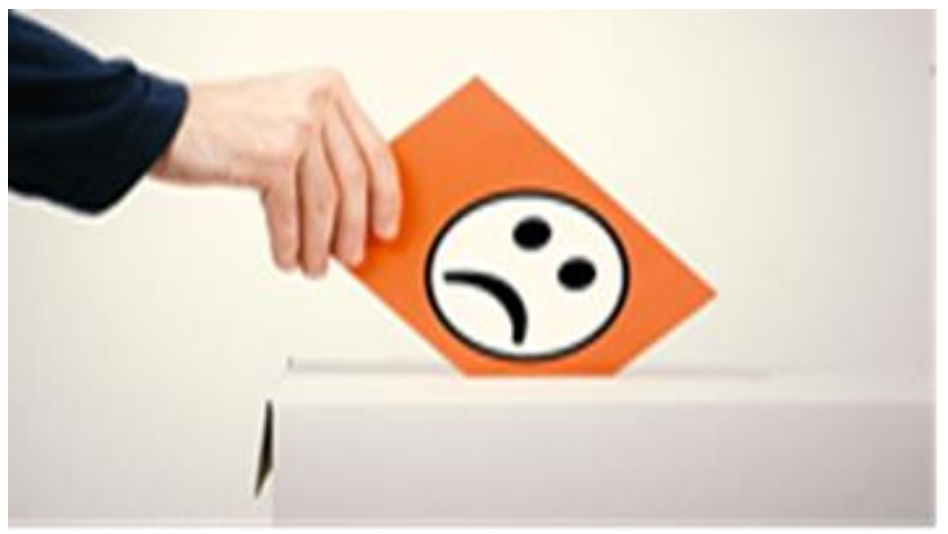

Picture 1. The opinions on the employment benefits of being the first graduates of the department of exercise and sports education for the disabled being the first department in this field in Turkey

The participants stated negative opinions on the employment benefits of being the first graduates of the Department of Exercise and Sports Education for the Disabled that was opened for the first time in Turkey. Some of the opinions of participants are as follows;

P2: As the first example in Turkey, I expect special appointment for our department in return for our education, internships and experiences and to serve my profession under the due status and conditions.

P5: Unfortunately, this department being a first in its field couldn't provide us a promising employment opportunity. We are still waiting hopefully.

P6: I am eagerly looking forward to working with my own students in my own graduation field together with a correction job description.

P11: I don't have any expectation from this department. We may have expectations if we see enough support and appointment from universities and institutions authorized for employment.

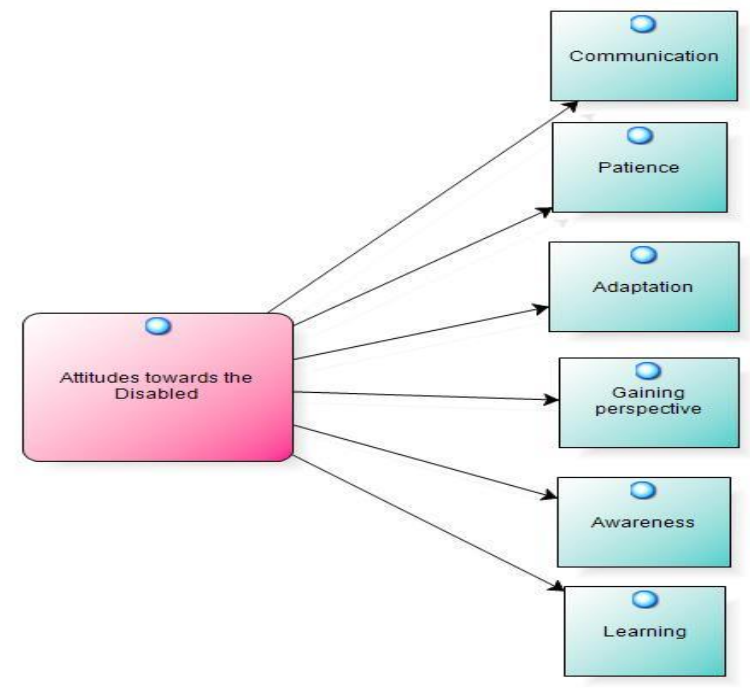

Model 3. Attitudes towards the Disabled 
The opinions of participants regarding their attitudes towards the disabled as being the graduates of the Department of Exercise and Sports Education for the Disabled were expressed as communication, patience, adaptation, gaining perspective, awareness and learning. Some of the opinions of participants are as follows;

P1: I am aware of our profession during the education process. I have found the opportunity of being in personal communication with students and providing education. I have felt that it has tough aspects and requires self-devotion and patience.

P2: It has changed, for sure. We learned a lot about the disabled, which changed our perspective towards them in many ways.

P3: It has changed a lot and I have understood that there is nothing they can't achieve if they are given sufficient opportunities and care by allowing them to have fun while I provide benefit to them and help them adapt to society with sports not only with the sense of pity and mercy but also from the eyes of an expert.

P5: Unlike other (some) people, I have always sought for the answers of such questions as; How can I be beneficial, how can I both have fun and teach? Instead of pitying them.

I'm more interested in looking at things in different ways and see the positive aspects of a negative situation.

P7: It has changed, for sure. Since I have knowledge about how I can contribute to the disabled individuals thanks to my education and internships during my undergraduate study, I also know how to contribute to their development.

P10: One of the contributions of this department for me is the sense of awareness towards the disabled. As you are more familiar with the disabled, you can better understand what problems they have in their social life and their private lives and you can approach them with a different perspective than ever before.

\section{Conclusion and Discussion}

The participants expressed their opinions about the future of the Department of Exercise and Sports Education for the Disabled that there wouldn't be any problem of employment (Private and Public sector) and appointments would be made immediately (Public). It was deemed suitable for the Department of Exercise and Sports Education for the Disabled to accept students in the General Meeting of Higher Education Dated 12.05.2011 for 2011-2012 academic year and the students were started to be accepted to this department for the first time in Turkey (İnönü Üniversitesi, 2018).Some people are hopeful about the future of the first graduates of this department while others are full of anxiety. It is observed that the graduates of this department experience some employment problems due to the lack of a job description.

It can be stated that the field education of the pedagogues who will work with the disabled people - being one of the disadvantaged groups - will play an important role in terms of the qualifications of the work they will do, the adaptation of the disabled to the society and the adoption of the principle of equality as an individual. The graduates of the department of exercise and sports education for the disabled are thought to make a great contribution to help the disabled individuals get a job in line with their own knowledge, skills and abilities following their education and rehabilitation period.

The opinions of participants regarding their attitudes towards the disabled as being the graduates of the Department of Exercise and Sports Education for the Disabled were expressed as communication, dedication, patience, adaptation, gaining perspective, awareness and learning. In the study of Yllmaz et al. (2014), it has been determined that sports activities are of great importance both for the daily life activities of the physically disabled individuals and their quality of life.They help individuals overcome their disabilities and contribute to their personalities through communication, socialization, having fun and positive motivation. It is thought that the interaction between the instructor and the disabled individuals will be higher if this kind of sports / recreational activities are performed by the experts in their fields.

Çelik (2008) has found that the empathic tendency levels of female teachers working in the field of special education are higher than the empathic tendency levels of male teachers and this condition has been interpreted in the way that this can be related to the maternal instinct and being understanding towards individuals.

In the research of Yildırım et al. (2010) conducted on nursing students, it has been established that the attitudes of relatively older and female students being in the final periods of their education towards the disabled individuals have been found to be significantly high. Similar results have also been reached in our study and the curriculum for the disabled can be stated to be an important process in changing the perspectives of the participants towards the disabled positively.

It has been concluded that the professional anxiety and expectations of the Department of Exercise and Sports Education for the Disabled - which will also ensure the socialization and integration of the disabled individuals into the 
sports in Turkey - and of the graduates of this department should be met and significant projects and job description will contribute to the development of this field in order to ensure national and international developments for the country in this field.

\section{References}

Alpman, C. (2001). Physical Education and the Development of Ages in the Integrity of Education. Can Publishing, Ankara.

Arslan, C. (2014). Türkiye'de Bir Ilk Olan Engellilerde Egzersiz Ve Spor Eğitimi Bölümünün Kuruluş ve Gerekçeleri. The Abstract Book of the 2th International Physical Education And Sports Congress for the Disabled, May, Batman.

Çelik, E. (2008). A Research Regarding The Emphatic Tendencies of Preschool Education Teachers In Terms of Some Variables, Master Thessis, Selçuk University / Institute of Social Sciences, Konya.

Cohen, L., Manion, L., \& Morrison, K. (2007). Research methods in education. New York: Routledge. https://doi.org/10.4324/9780203029053

Gallahue, D. L., \& Omzun, J. C. (1995). Understanding Motor Development. U.S.A.

Girgin, M. C. (2003). Introduction to the education of hearing impaired children. Anadolu University Publishing, Eskişehir.

Hannon, F. (2005). Promoting the participation of people with disabilities in physical activity and sport in Ireland. Paralympics Council of Ireland and Federation of Disability Sports. Disability Research Series 3.

İnönü Üniversitesi (2018). Official Web Site. Access link: http://inonu.edu.tr/tr/eeseb/1751/menu?m=6449 Access Date: 11.09.2018

Merriam, S. B. (2013). A Guide for Qualitative Research Design and Practice. Nobel Academic Publishing, Ankara.

Payne, V. G., \& Isaacs, L. D. (2005). Human motor Development: A Lifespan Approach (6th ed.). Bosm ton: McGraw-Hill.

Ritchie, J., \& Lewis, J. (2003). Qualitative research practice. London: SAGE Publications.

Sherrill, C. (2010). Young people with disability in physical education/physical activity/sport in and out of schools: Technical Report for the World Health Organization. WHO.

Yıldırım, A., \& Şimşek, H. (2008). Qualitative research methods in the social sciences. Ankara: Seçkin Publishing.

Yıldırım, S. H., Bektaş, M., \& Altıparmak, S. (2010). Determining the Attitudes of Nursing Students Towards Disabled People. New Health Journal, 27, 80-83.

Yılmaz, A., Şentürk, U., \& Ramazanoğlu, F. (2014). Content Analysis of Sports Research on Physically Disabled People. Sport Management and Knowledge Techonologies, 9(1-2).

\section{Copyrights}

Copyright for this article is retained by the author(s), with first publication rights granted to the journal.

This is an open-access article distributed under the terms and conditions of the Creative Commons Attribution license which permits unrestricted use, distribution, and reproduction in any medium, provided the original work is properly cited. 